\title{
The Compromise Condition for High Performance of the Single Silicon Heterojunction Solar Cells
}

\author{
Youngseok Lee, ${ }^{1}$ Vinh Ai Dao, ${ }^{2,3}$ Sangho Kim, ${ }^{1}$ Sunbo Kim, ${ }^{3}$ Hyeongsik Park, ${ }^{3}$ Jaehyun Cho, ${ }^{3}$ \\ Shihyun Ahn, ${ }^{3}$ and Junsin $\mathrm{Yi}^{1,3}$ \\ ${ }^{1}$ Department of Energy Science, Sungkyunkwan University, Suwon 440-746, Republic of Korea \\ ${ }^{2}$ College of Science, Faculty of Materials Science, Vietnam National University, 227 Nguyen Van Cu, Hochiminh, Vietnam \\ ${ }^{3}$ School of Information and Communication Engineering, Sungkyunkwan University, Suwon 440-746, Republic of Korea
}

Correspondence should be addressed to Junsin Yi, yi@yurim.skku.ac.kr

Received 31 August 2011; Revised 14 November 2011; Accepted 14 November 2011

Academic Editor: C. W. Lan

Copyright (c) 2012 Youngseok Lee et al. This is an open access article distributed under the Creative Commons Attribution License, which permits unrestricted use, distribution, and reproduction in any medium, provided the original work is properly cited.

\begin{abstract}
For optimum performance of the hydrogenated amorphous silicon/crystalline silicon (a-Si : H/c-Si) heterojunction solar cells, featuring a doping concentration, localized states, as well as thickness of emitter layer are crucial, since Fermi level, surface passivated quality, and light absorption have to be compromised themselves. For this purpose, the effect of both doping concentration and thickness of emitter layer was investigated. It was found that with gas phase doping concentration and emitter layer thickness of $3 \%$ and $7 \mathrm{~nm}$, solar cell efficiency in excess of $14.6 \%$ can be achieved. For high gas phase doping concentration, the degradation of open-circuit voltage as well as cell efficiency was obtained due to the higher disorder in the emitter layer. The heavily doped along with thicker in thickness of emitter layer results in light absorption on short wavelength, then diminishing short-circuit current density.
\end{abstract}

\section{Introduction}

Heterojunction solar cells consisting of crystalline silicon (c$\mathrm{Si}$ ) and hydrogenated amorphous silicon (a-Si:H) offer a low cost and high efficiency energy conversion alternative to conventional crystalline silicon solar cells. Compared to conventional silicon solar cells with diffused $\mathrm{n} / \mathrm{p}$ junction and back surface field layers (BSF), noteworthy cost reduction can be obtained due to a completely low temperature $(\sim$ $200^{\circ} \mathrm{C}$ ) formation process for both the $\mathrm{n} / \mathrm{p}$ junction and BSF layer using hydrogenated amorphous silicon technology. Presently, Sanyo's heterojunction with intrinsic thin layer (HIT) solar cells showed the world record efficiency of $23 \%$ for double-junction structure [1]. However, for the singlejunction HIT solar cell fabricated on polished wafers has reported approximately $13 \sim 14 \%$ efficiency [2-6], in which the open-circuit voltage $\left(V_{\text {oc }}\right)$ did not exceed $580 \mathrm{mV}$, and the fill factor $74 \%$ could be obtained. Beside Sanyo, most research groups have been working on single-junction HIT solar cell using p-type c-Si as a base substrate.

When using a-Si:H and c-Si for junction formation, there are different aspects to be taken into account. Firstly to obtain high open circuit voltage $\left(V_{\text {oc }}\right)$ and thus efficiency, the Fermi level in the emitter layer should be as close as to the nearest band as possible, which means that doping concentration is as high as it could be. The high doping concentration, nevertheless, also results in the high defect density in the films and leads to enhanced surface recombination [4]. The preferred doping concentration of emitter for HIT solar cell performance is still a matter of discussion. Sanyo's group has held world record efficiency of $23 \%$, despite of, the limitation outside of Sanyo because of improper deposition condition such as doping concentration and so on. E. Conrad et al. suggested an optimal doping concentration $\left(\mathrm{B}_{2} \mathrm{H}_{6} / \mathrm{SiH}_{4}\right)$ of around 2000-3000 ppm [7]. Using simulation, N. Hernández-Como et al. proposed that the efficiency increases with increasing emitter doping concentration. Above a concentration of $3 \times 10^{19}\left(\mathrm{~cm}^{-3}\right)$, the solar cell efficiency reaches its saturation value [8].

Also the emitter thickness variation could determine the short-circuit current as well as built-in potential in case of very thin layer of a-Si: $\mathrm{H}(\mathrm{p})$. On raising the emitter thickness, a-Si : H(p) layer incorporated into solar cells acts as a "dead 
layer" and no electrons generated within the emitter layer are extracted due to intense carrier recombination within the defect emitter layer [9]. Reports on the optimum conditions varied in the literature and they can be classified roughly into two groups. Most research groups argue that $4 \sim 5 \mathrm{~nm}$ is thick enough for good device performances $[1,9]$. While, emitter thickness of around $15 \mathrm{~nm}$ is mentioned to be thin enough by another [10]. In this paper, the compromise conditions for doping concentration, as well as the thickness of emitter layer, were investigated to set up a baseline for single $\mathrm{p} / \mathrm{n}$ heterojunction solar cells.

\section{Experiment}

The commercial Czochralski-grown (CZ) c-Si(n) substrate with $\langle 100\rangle$ orientation, resistivity of $1-10 \Omega \cdot \mathrm{cm}$, and $525 \mu \mathrm{m}$ thickness has been used to fabricate the HIT solar cells. The crystalline Si substrates were treated by a sequence consisting of (1) acetone/methanol/DIW cleaning, (2) RCA cleaning. Native oxide was removed by a $1 \mathrm{~min}$. dip in $1 \%$ hydrofluoric acid right before a-Si: $\mathrm{H}$ deposition. To change the doping concentration of the a-Si: $\mathrm{H}$ emitter, the gas phase doping concentration, $\mathrm{B}_{2} \mathrm{H}_{6} / \mathrm{SiH}_{4}$, was varied in range of 2 to $10 \%$, while the thickness of the a-Si: $\mathrm{H}$ emitter was fixed at $7 \pm 0.05 \mathrm{~nm}$. For the emitter thickness variation set, the gas phase doping concentration was $3 \%$, the optimization condition in previous set, while emitter thickness varied in range of $3-15 \mathrm{~nm}$. For the transparent conductive oxide (TCO), Indium Tin Oxide (ITO) thin film was deposited by rf magnetron sputtering at a substrate temperature of $200^{\circ} \mathrm{C}$ with thickness of about $80 \pm 5 \mathrm{~nm}$, followed by the deposition of silver/aluminum finger as the emitter contacts. Aluminum was evaporated on backside to create a good ohmic contact prior to area defining with mesa etching.

As confirmed previously [11], the a-Si: $\mathrm{H}(\mathrm{p})$ layer thickness controlled by spectroscopy ellipsometry (SE) shows excellent agreement with one evaluated from transmission electron microscopy (TEM). Hence, ellipsometry spectra $(\psi, \Delta)$ were collected using a rotating-compensator instrument (J. A. Woollam, HR-190) in this study. For the analysis, we used an optical model consisting of ambient/surface roughness layer $(\mathrm{a}-\mathrm{Si}: \mathrm{H}(\mathrm{p})$ )/bulk layer (a$\mathrm{Si}: \mathrm{H}(\mathrm{p})) / \mathrm{SiO}_{2} /$ substrate ( $n$-type c-Si), as shown in Figure 1. The dielectric function of the surface roughness layer was modeled as a 50/50 vol.\% mix bulk layer material and voids [12]. The dielectric function of the a-Si:H(p) layer was modeled by the Tauc-Larentz (TL) model [12], which is expressed by

$$
\begin{gathered}
\varepsilon_{\mathrm{imTL}}(E) \frac{A \cdot E_{0} \cdot C \cdot\left(E-E_{g}\right)^{2}}{\left(E^{2}-E_{g}\right)^{2}+C^{2} \cdot E^{2}} \cdot \frac{1}{E} \quad E>E_{g}, \\
\varepsilon_{\mathrm{imTL}}(E)=0 \quad E \leq E_{g},
\end{gathered}
$$

where $E_{0}$ is the peak transition energy, $E_{g}$ is the energy gap, and $C$ is a broadening parameter, which can be related to the degree of disorder in the material. $A$ is proportional to the height of imaginary part of the dielectric function. The

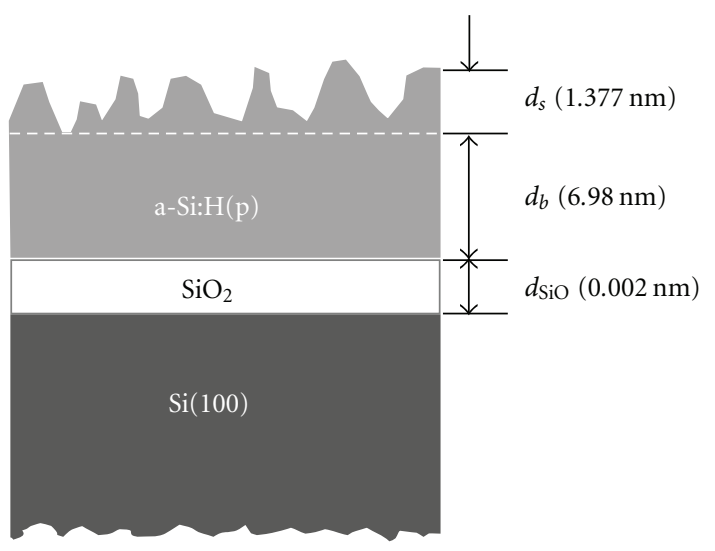

Figure 1: Optical model used for a-Si:H(p) layer formed on $\operatorname{Si}(100)$ substrates. The thickness for surface roughness layer, a$\mathrm{Si}: \mathrm{H}(\mathrm{p})$ layer, and $\mathrm{SiO}_{2}$ layer is denoted as $d_{s}, d_{b}$, and $d_{\mathrm{SiO}}$, respectively. The back-surface of the $\mathrm{Si}(100)$ substrate was roughened to eliminate back-side light reflection.

parameters of the dielectric function, the thickness of the films, and their roughness are obtained by analysis of the spectra using TL model. The values of the various parameters are reported in Table 1. To determine hetero-interface quality, the minority carrier lifetime $\left(\tau_{\text {eff }}\right)$ was measured by the quasi-steady-state photoconductance (QSSPC) method, using a commercial WCT-120 photoconductance setup from Sinton Consulting. The electrical characteristics and activation energy were studied using the coplanar method with a programmable Keithley 617 electrometer using the samples grown on the glasses. The optical transmittance was measured in the wavelength range of $300-1200 \mathrm{~nm}$ using UV-Vis spectrophotometer. The external quantum efficiency (EQE) measurements of heterojunction solar cells were performed by using xenon lamp, a monochromator, and optical filters to filter out the high orders with a light probe beam impinging normal on the sample. The solar cells were characterized by current-voltage measurement under AM1.5 conditions at $25^{\circ} \mathrm{C}$.

\section{Results and Discussion}

From Figure 2, it is observed that the $E_{a}$ decreases rapidly when $X_{g}\left(X_{g}=\left[B_{2} \mathrm{H}_{6}\right] /\left[\mathrm{SiH}_{4}\right]\right)$ is increased from $2 \%$ to $3 \%$ and then it seems to saturate with further increase. As evidence from Figure 2(a), the minimum $E_{a}$ is obtained for $X_{g}=10 \%$ and thus the best device performance should be obtained using this gas phase doping concentration. However, contrary to our expectations, the highest performance of device is observed for $X_{g}=3 \%$. The efficiency decreases for both higher and lower gas phase doping concentration. A similar variation is also observed for short-circuit current density $\left(J_{\mathrm{sc}}\right)$. The $V_{\text {oc }}$ increases to a value of around $590 \mathrm{mV}$ with the increasing in $X_{g}$ of $3 \%$ and then seems to linearly shrink for further increase of $X_{g}$ increases.

Figure 3 summarizes the degree of disorder $(C)$ in a$\mathrm{Si}: \mathrm{H}(\mathrm{p})$ and minority carrier lifetime $\left(\tau_{\text {eff }}\right)$ of a-Si:H(p) 
TABLE 1: Best-fit parameters extracted from the dielectric function modeling using the Tauc-Lorentz model. The results were obtained from the a-Si : H(p) thin films deposited at different gas phase doping concentrations.

\begin{tabular}{|c|c|c|c|c|c|c|c|}
\hline$X_{g}$ & $d_{s}(\mathrm{~nm})$ & $d_{b}(\mathrm{~nm})$ & $d_{\mathrm{SiO}}(\mathrm{nm})$ & $A$ & $E_{0}(\mathrm{eV})$ & $C$ & $E_{g}(\mathrm{eV})$ \\
\hline $2 \%$ & 1.978 & 7.082 & 0.052 & 80.88 & 3.97 & 1.69 & 1.62 \\
\hline $3 \%$ & 1.377 & 6.980 & 0.002 & 83.67 & 3.91 & 1.75 & 1.62 \\
\hline $5 \%$ & 0.909 & 7.071 & 0.154 & 93.96 & 3.84 & 1.82 & 1.59 \\
\hline $10 \%$ & 1.880 & 6.992 & 0.032 & 95.75 & 3.83 & 1.97 & 1.60 \\
\hline
\end{tabular}

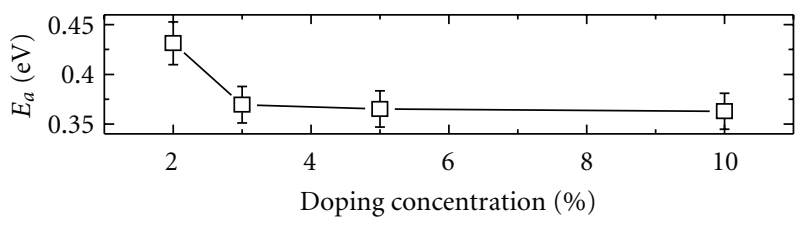

(a)

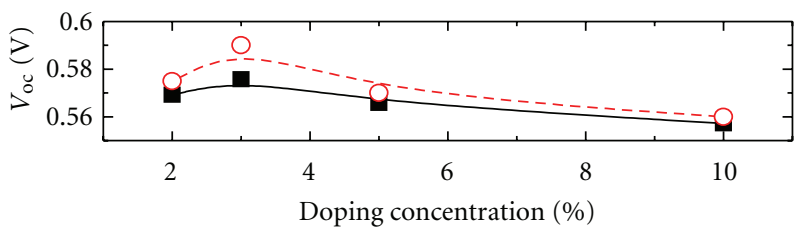

(c)

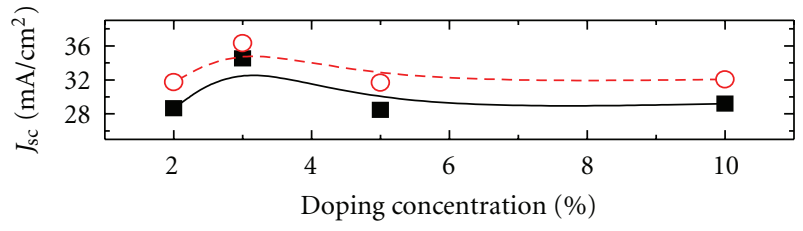

(b)

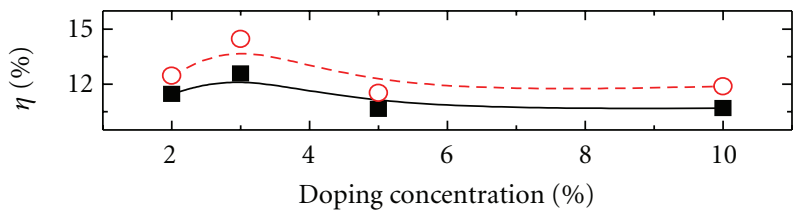

- Average

- o- Maximum

(d)

FIgure 2: The activation energy, $E_{a}$, of a-Si: H(p) deposited on glass (a) and performance of Al/Ag/ITO/a-Si: $\mathrm{H}(\mathrm{p}) / \mathrm{c}-\mathrm{Si}(\mathrm{n}) / \mathrm{Al}$ solar cells $(b-d)$ with varying gas phase doping concentration of the a-Si: $\mathrm{H}(\mathrm{p})$.

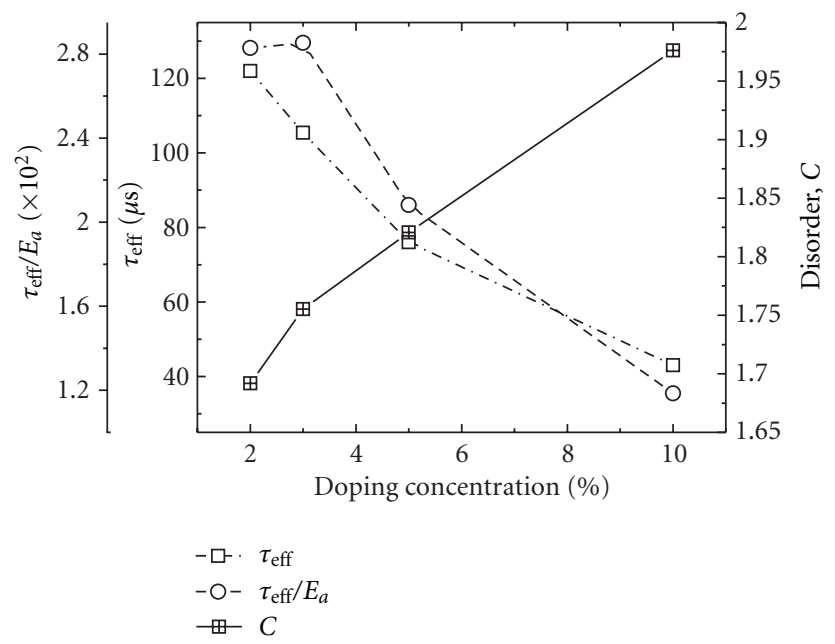

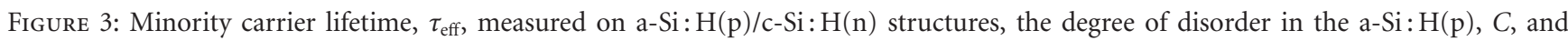
trade-off factor, $O p t=\tau_{\text {eff }} / E_{a}$, as a function of the gas phase doping concentration.

deposited on $\mathrm{c}-\mathrm{Si}(\mathrm{n})$ as a function of gas phase doping concentration of emitter layer. It is note that the $C$ value is obtained from a well fit of the dielectric function of a-Si:H(p) using Tauc-Lorentz model, as discussing in the experimental part. It is clear that the trend of $\tau_{\text {eff }}$ and $C$ displays a contrary direction and hence this also could be the reason for the reducing of $V_{\mathrm{oc}}$ when $X_{g}$ is increased. As reported by R. A. Street, substitutional doping of a$\mathrm{Si}: \mathrm{H}(\mathrm{p})$ leads to the creation of deep defects [13]. This leads to a self-compensation effect in a-Si:H(p). Hence, the disorder in the a-Si:H(p) leads to a higher amount of interface states and thus a decreased minority carrier lifetime of a-Si:H(p)/c-Si(n) heterojunction. By increasing gas phase doping concentration, eventually, on the one hand the band bending increases with increasing gas phase doping concentration, on the other hand the disorder in the a$\mathrm{Si}: \mathrm{H}$ layer and interface states (decrease in $\tau_{\text {eff }}$ ) increases. Therefore, we suggest a new factor $\left(O p t=\tau_{\text {eff }} / E_{a}\right)$ that may 

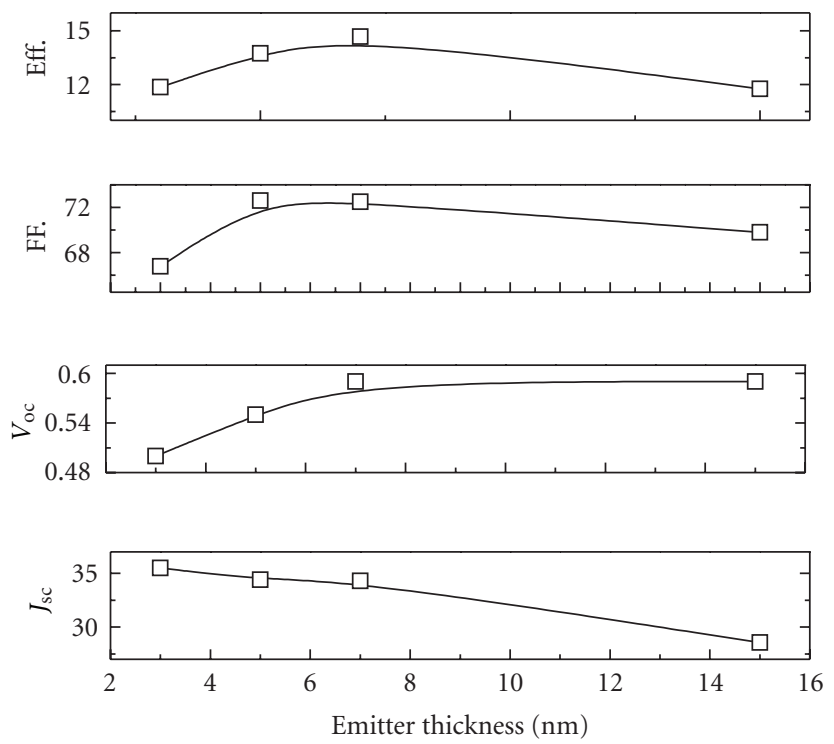

Figure 4: Solar cell parameters, short-circuit current density, open-circuit voltage, fill factor, and efficiency, as a function of a-Si:H(p) thickness for a-Si: $\mathrm{H}(\mathrm{p}) / \mathrm{c}-\mathrm{Si}(\mathrm{n})$ heterojunction solar cells.

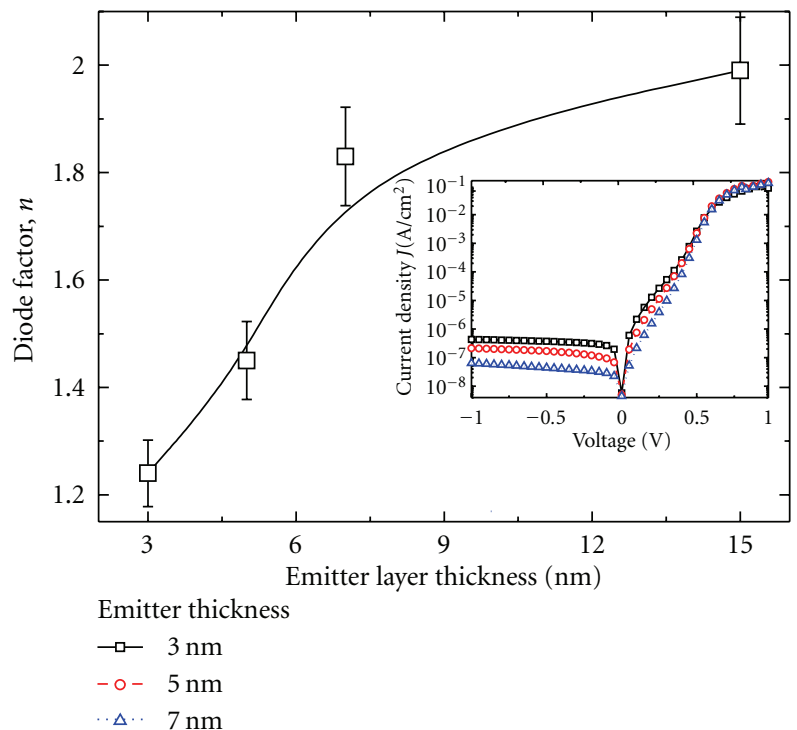

FIGURE 5: The diode factor $n$ versus emitter layer thickness obtained from dark-current density versus voltage (DIV) with a-Si: H(p)/c-Si(n) solar cells shown in Figure 4. The inset shows DIV for a-Si : H(p)/c-Si(n) solar cells having different emitter layer thickness.

be presented as a trade-off between interface states and the position of the Fermi energy as showed in Figure 3. The highest $O p t$ value is achieved at gas doping concentration of $3 \%$ and it is also point of merit for achieving highest device performance.

The parameters of an a-Si:H(p)/c-Si(n) solar cell, plotted as a function of the a-Si:H(p) emitter-layer thickness are shown in Figure 4. With increasing emitter-layer thickness up to $7 \mathrm{~nm}, V_{\text {oc }}$ increases linearly and then saturates beyond this layer thickness. It should be mentioned that for thickness smaller than $7 \mathrm{~nm}$ the open circuit voltage drops down to values around $500 \mathrm{mV}$. According to the usual junction rectification models for HIT solar cell at high forward bias voltage region $(0.4<V<0.6 \mathrm{~V})$, a relation between $J$ and $V$ is presented simply by [9]

$$
J=J_{0}\left[\exp \left(\frac{q V}{n K T}\right)-1\right]-J_{\mathrm{ph}}
$$

where $J_{0}$ and $J_{\mathrm{ph}}$ are the saturation current density and photocurrent density, respectively. $q, n, k$, and $T$ denote electron charge, diode factor, Boltzmann's constant, and temperature, respectively. Since $\exp [q V / k T] \gg 1$ at $\mathrm{V} \sim 0.5 \mathrm{~V}$ and $T=300 \mathrm{~K}, J_{0}$ and $n$ can be determined directly from the intercept and slope of $J-V$ characteristics by applying (2) with using dark-current density versus voltage, as shown in the inset of Figure 5. From Figure 5 we observed that 

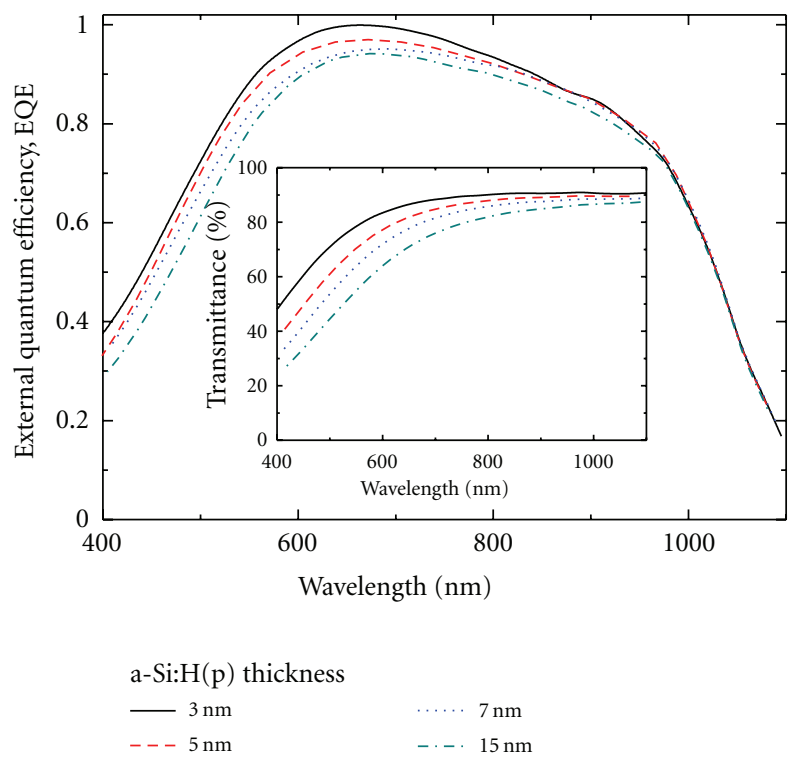

FIGURE 6: Variation of external quantum efficiency (QE) spectrum with a-Si:H(p) thickness. The inset shows that transmittance of a$\mathrm{Si}: \mathrm{H}(\mathrm{p})$ with different thickness was deposited on glass substrate.

$n \approx 1.25$ was obtained for a-Si:H(p) thickness of $3 \mathrm{~nm}$ and then this values increase with further increasing in layer thickness. The maximum of $n \approx 1.9$ was observed for layer thickness of $15 \mathrm{~nm}$. Thus conduction mechanisms in our device are shifted from diffusion-recombination to recombination for thicker in emitter layer. The diffusionrecombination dominated for thinner emitter layer could be attributed to a smaller built-in potential in the ITO/a$\mathrm{Si}: \mathrm{H}(\mathrm{p}) / \mathrm{c}-\mathrm{Si}(\mathrm{n})$ structure [9], leading to low $V_{\mathrm{oc}}$. A similar variation with $V_{\mathrm{oc}}$ is also observed for $F F$ with emitter thickness less than $7 \mathrm{~nm}$; however, after passing through an optimum where the $F F$ was maximized, a further increasing in emitter layer thickness resulted in a significant decrease of F.F. This could be owing to the serial resistance component and also a lesser probability of tunneling of holes through a$\mathrm{Si}: \mathrm{H}(\mathrm{p})$ layer as thickness increases.

In contract to $V_{\mathrm{oc}}, J_{\mathrm{sc}}$ reduces with increasing emitterlayer thickness. As a result, we obtained a solar cell efficiency of $14.6 \%\left(V_{\mathrm{oc}}=590 \mathrm{mV}, F F=0.72\right.$, and $\left.J_{\mathrm{sc}}=34.3 \mathrm{~mA} / \mathrm{cm}^{2}\right)$ at the optimum thickness of $p=7 \mathrm{~nm}$ without the incorporation of surface texture, intrinsic hydrogenated amorphous silicon. In Figure 6, the external quantum efficiency (QE) spectrum as a function a-Si:H(p) thickness was depicted. For convincing, transmittance of a-Si:H(p) layer with difference thickness was also measured and shown in the inset of Figure 6. It is clear that the thicker in emitter layer leads to lower in transmittance due to Lambert-Beer law. Thus, the QE of the thinner film is enhanced especially in the short wavelength region where the absorption of the a-Si:H films is low. Hence, the reduction in $J_{\text {sc }}$ shown in Figure 4 may come from the degradation of the short wavelength response. It is well known that heavily doped $\mathrm{a}-\mathrm{Si}: \mathrm{H}$ layers generally exhibit quite high defect densities of $\sim 10^{18} \mathrm{~cm}^{-3}$, which is close to the defect densities of our a-Si:H(p) layer $\left(2.33 \sim 3.70 \times 10^{18} \mathrm{~cm}^{-3}\right)$, separately estimated by ellipsometry measurement on a-Si:H(p) films deposited on glass substrate. Due to its structure disorder and high doping, on the one hand, the diffusion length of the carrier in amorphous silicon layer is so small that only drifts current but no diffusion current can occur. On the order hand, the penetration depth of the space charge region in the $\mathrm{a}-\mathrm{Si}: \mathrm{H}$ side is so small that there is no electric field inside the layer. Thus, a heavily doped a-Si : H(p) layer incorporated into the heterojunction solar cells acts as a "dead layer". For that reason it has to be as thin as possible.

\section{Conclusion}

In conclusion, the a-Si:H(p)/c-Si(n) heterojunction solar cell was set up for future development of high efficiency heterojunction with intrinsic thin (HIT) layer solar cells. The correlation between doping concentration, a-Si:H(p) layer thickness, and cell performance was discussed. An optimum value for gas phase doping concentrations of a$\mathrm{Si}: \mathrm{H}(\mathrm{p})$ was found to be $3 \%$. For high gas phase doping concentrations, on the one hand the band bending increases with increasing gas phase doping concentration, on the other hand the disorder in the a-Si:H layer and interface states (decreases in $\tau_{\text {eff }}$ ) increases. Hence, solar cell efficiency degrades. The a-Si:H(p) thickness of $7 \mathrm{~nm}$ is optimum for $\mathrm{a}-\mathrm{Si}: \mathrm{H}(\mathrm{p}) / \mathrm{c}-\mathrm{Si}(\mathrm{n})$ heterojunction solar cell. Degradation of open-circuit voltage or short-circuit current density and hence efficiency was observed for thinner or thicker layers. Using optimized conditions, we obtained $14.67 \%$ efficiency for the $\mathrm{a}-\mathrm{Si}: \mathrm{H}(\mathrm{p}) / \mathrm{c}-\mathrm{Si}(\mathrm{n})$ structure.

\section{Acknowledgment}

This research was supported by WCU (World Class University) program through the National Research Foundation 
of Korea funded by the Ministry of Education, Science and Technology (R31-2008-000-10029-0).

\section{References}

[1] T. Mishima, M. Taguchi, H. Sakata, and E. Maruyama, "Development status of high-efficiency HIT solar cells," Solar Energy Materials and Solar Cells, vol. 95, no. 1, pp. 18-21, 2011.

[2] K. Wakisaka, M. Taguchi, T. Sawada et al., "More than $16 \%$ solar cells with a new "HIT" (doped a-Si/non-doped a$\mathrm{Si} /$ crystalline $\mathrm{Si}$ ) structure," in Proceedings of the 22nd IEEE Photovoltaic Specialists Conference, p. 887, Las Vegas, Nev, USA, 1991.

[3] Q. Wang, M. R. Page, Y. Xu, E. Iwaniczko, E. Williams, and T. H. Wang, "Development of a hot-wire chemical vapor deposition n-type emitter on p-type crystalline Si-based solar cells," Thin Solid Films, vol. 430, no. 1-2, pp. 208-211, 2003.

[4] K. V. Maydell, L. Korte, A. Laades et al., "Characterization and optimization of the interface quality in amorphous/crystalline silicon heterojunction solar cells," Journal of Non-Crystalline Solids, vol. 352, no. 9-20, pp. 1958-1961, 2006.

[5] K. V. Maydell, M. Schmidt, L. Korte et al., "Basic electronic properties and optimization of TCO/a-Si:H(n)/c-Si(p) hetero solar cells," in Proceedings of the 31st IEEE Photovoltaic Specialists Conference, pp. 1225-1228, January 2005.

[6] D. Borchert, G. Grabosch, and W. R. Fahrner, "Preparation of (n) a-Si : H/(p) c-Si heterojunction solar cells," Solar Energy Materials and Solar Cells, vol. 49, no. 1-4, pp. 53-59, 1997.

[7] E. Conrad, L. Korte, K. V. Maydell et al., "Development and optimization of a-Si:H/c-Si heterojunction solar cells completely processed at low temperatures," in Proceedings of the 21st European Photovoltaic Solar Energy Conference, Dresden, Germany, September 2006.

[8] N. Hernández-Como and A. Morales-Acevedo, "Simulation of hetero-junction silicon solar cells with AMPS-1D," Solar Energy Materials and Solar Cells, vol. 94, no. 1, pp. 62-67, 2010.

[9] H. Fujiwara and M. Kondo, "Effects of a-Si:H layer thicknesses on the performance of a-Si:H/c-Si heterojunction solar cells," Journal of Applied Physics, vol. 101, no. 5, Article ID 054516, 9 pages, 2007.

[10] T. H. Wang, E. Iwaniczko, M. R. Page et al., "Effect of emitter deposition temperature on surface passivation in hot-wire chemical vapor deposited silicon heterojunction solar cells," Thin Solid Films, vol. 501, no. 1-2, pp. 284-287, 2006.

[11] H. Fujiwara and M. Kondo, "Real-time monitoring and process control in amorphouscrystalline silicon heterojunction solar cells by spectroscopic ellipsometry and infrared spectroscopy," Applied Physics Letters, vol. 86, no. 3, Article ID 032112, 3 pages, 2005.

[12] A. Fontcuberta I Morral, P. Roca I Cabarrocas, and C. Clerc, "Structure and hydrogen content of polymorphous silicon thin films studied by spectroscopic ellipsometry and nuclear measurements," Physical Review B, vol. 69, no. 12, Article ID 125307, 10 pages, 2004.

[13] R. A. Street, Hydrogenated Amorphous Silicon, Cambridge University Press, 1991. 


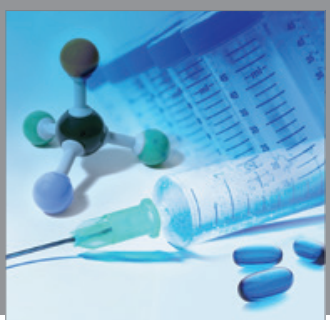

International Journal of

Medicinal Chemistry

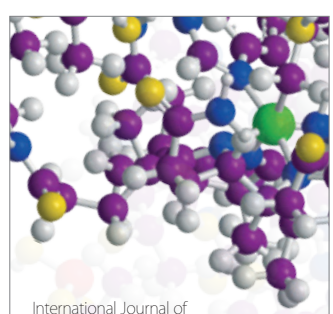

Carbohydrate Chemistry

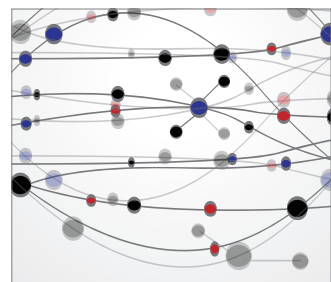

The Scientific World Journal
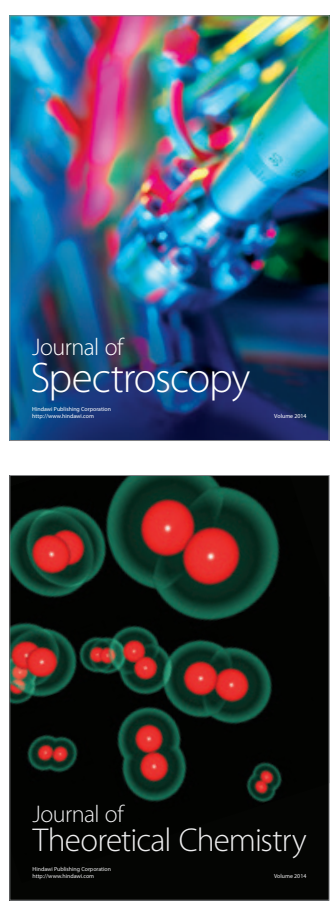
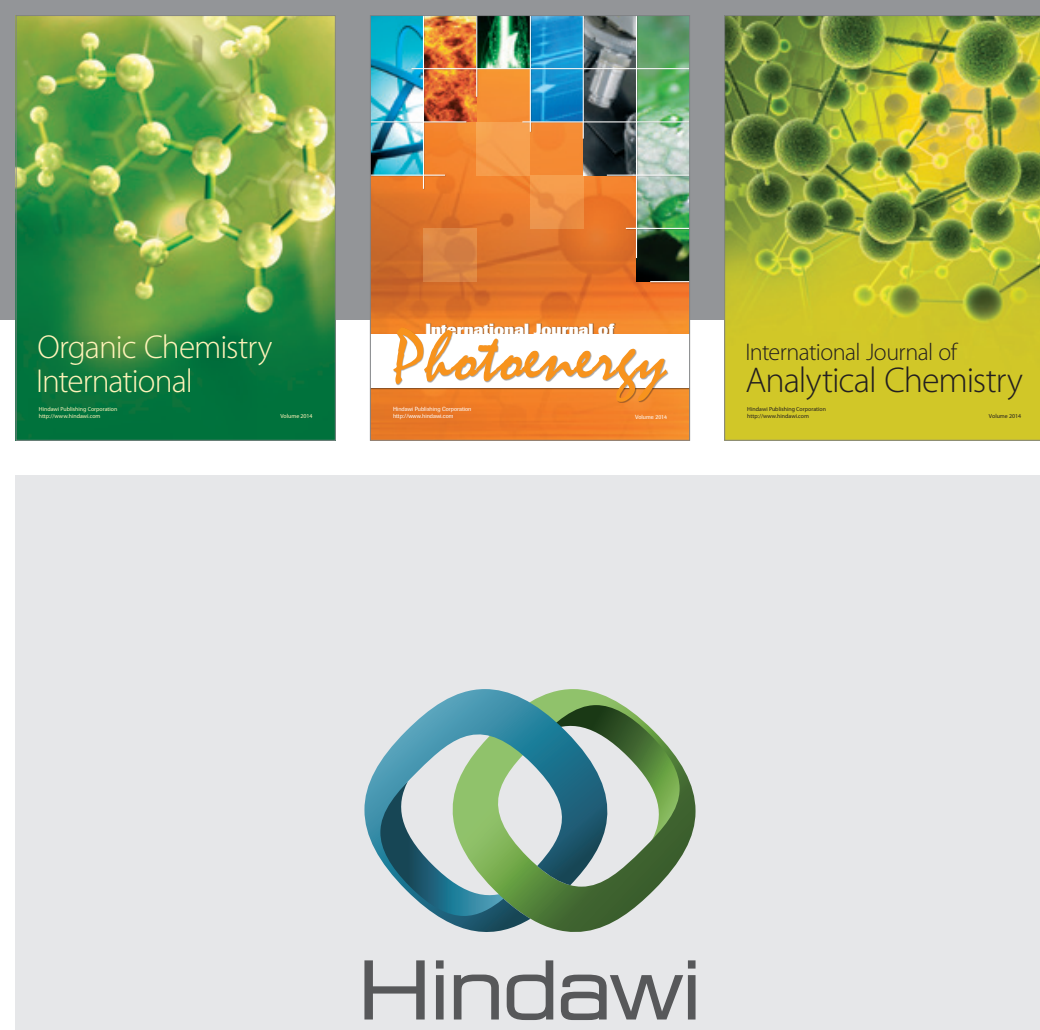

Submit your manuscripts at

http://www.hindawi.com
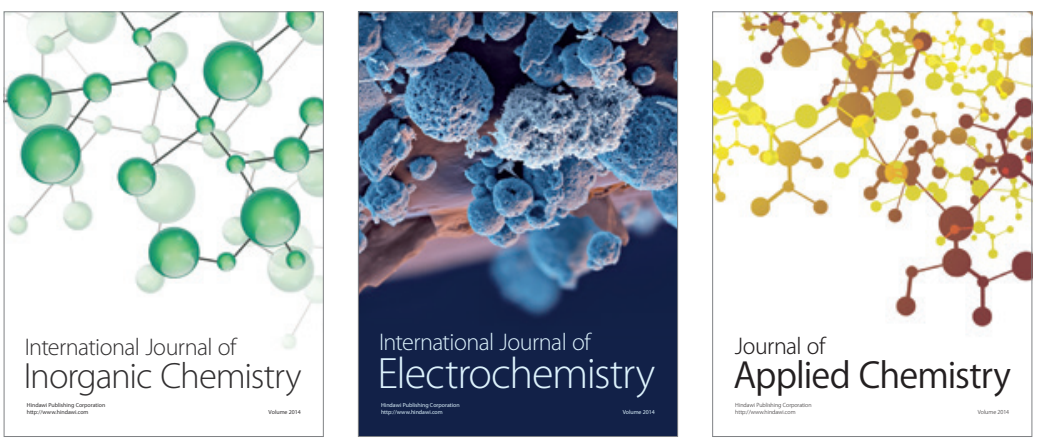

Journal of

Applied Chemistry
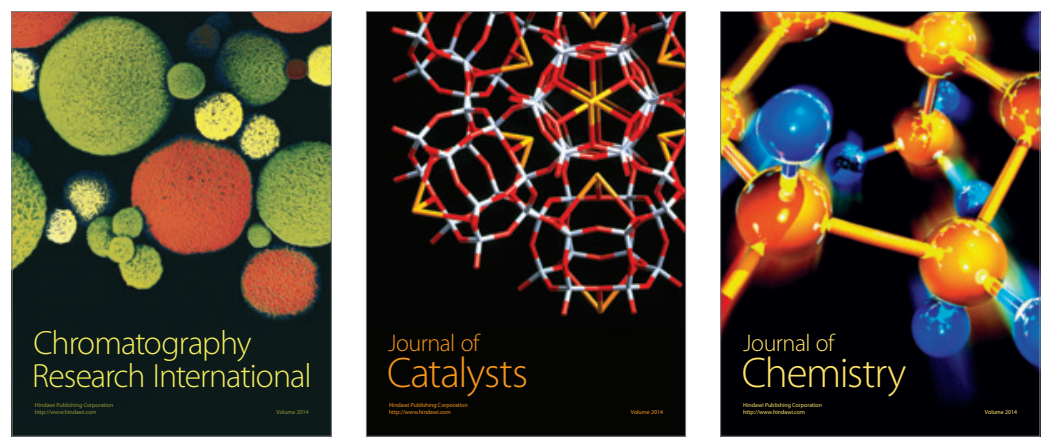
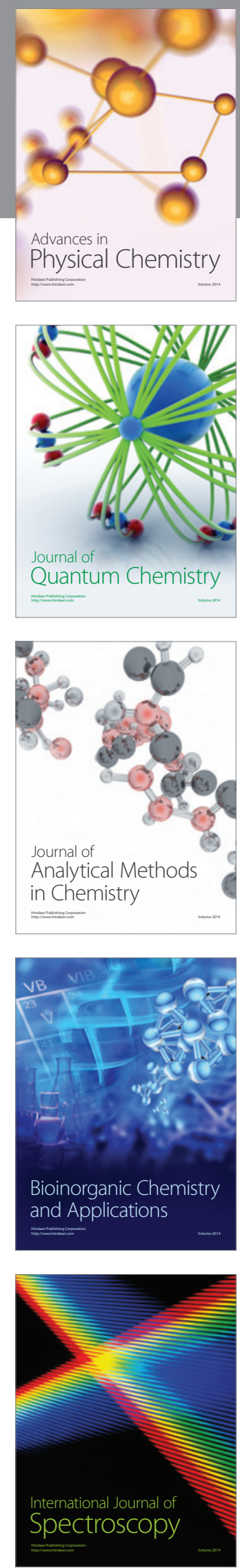